\title{
Proteins as Surfactant Enhancers for Environmental and Industrial Applications
}

Michael Goldfeld ${ }^{1 *}$, Andrew Malec ${ }^{1}$, Carl Podella ${ }^{1}$ and Christopher Rulison ${ }^{2}$

${ }^{1}$ Advanced BioCatalytics Corporation Irvine, California, USA

${ }^{2}$ Augustine Scientific, Newbury, Ohio, USA

\begin{abstract}
Data are presented on the effect of small proteins on the surface activity of synthetic surfactants and their blends as assessed by standard surface science methods. Surface tension of surfactant solutions, interfacial tension between those solutions and water insoluble substrates, and contact angle between these solutions and a solid surface were determined. It is shown that both small individual proteins, such as lysozyme and $\beta$-lactoglobulin, as well as proteins in a yeast extract, significantly and predictively reduce critical micelle concentration of multiple widely used surfactants: ionic, non-ionic and amphoteric. Typically, lower minimal interfacial tension could be achieved with a protein synergist, than with the same surfactant in the absence of protein. Examples of industrially important applications of a protein synergist are described. In one of them, the protein accelerates wetting and spreading of surfactant solutions on the hydrophobic surface of green leaves, with concomitant enhancement of the solution uptake by the leaf. In another example, the activity of bacterial lipase, an important industrial enzyme, towards a segregated oil substrate is enhanced by a surfactant-protein synergist blend, as compared to the same surfactant in the absence of a protein synergist.
\end{abstract}

Keywords: Critical micelle concentration; Proteins; Surfactant

\section{Introduction}

Studies of protein-surfactant interactions go back about a century, being inspired by broad practical implications. There is extensive literature on this topic [1-5]. However, most of the publications concentrate on the effect of surfactants on proteins, such as the unfolding and refolding of the protein coil, and the application of surfactants in isolation and purification of proteins, especially those incorporated into biological membranes. For water-soluble proteins, interactions with surfactants were broadly split up into two regions: below and above the surfactant's critical micelle concentration (CMC). With anionic surfactants (such as sodium lauryl sulfate) the binding to a protein (such as lysozyme) starts before the surfactant's CMC is achieved, leading to a plateau in the Gibbs isotherm at 15 to 20 surfactant molecules bound to each protein globule. After the CMC has been surpassed, further steep growth of binding was found. Below the surfactant's CMC, water-soluble protein may undergo a series of conformational changes as it is binding an increasing numbers of ionic surfactant molecules. The two major and discrete events in the perturbation of protein structure were briefly summed up as tertiary structure unfolding in the sub-micellar zone, and chain expansion in the micellar range of ionic surfactant concentrations [4]. In contrast, only very weak interactions with non-ionic surfactants were noticed in this sub-micellar concentration range.

Much less attention has been paid to the other side of the proteinsurfactant interaction phenomena, i.e. how proteins affect the behavior, and particularly the surface activity of amphiphilic chemicals used in detergents and cleaning agents. Within this latter context, it has been reasoned that the formation of free micelles may be shifted to higher surfactant concentrations in the presence of proteins, because the proteins may sequester surfactant molecules and thus reduce the concentration of free monomeric surfactant available for the formation of micelles [1]. Proteins, however, may also contribute to a formation of micelle-like surfactant clusters well below the CMC of the surfactant per se; these clusters can then interact with proteins, as well as with other species in their environment, in a very different manner than the bulk micelles. The situation is further complicated by the fact that the protein globule is a flexible structure, with multiple conformations accessible to it, each conformation close to each other in their energy, and separated by rather low energy barriers. Therefore, interactions with both monomeric surfactants and micelles may well result in conformational transitions of the protein, thus forming a set of multiple structures, likely to coexist, that might display different surface activities.

Meanwhile, if we have an accessible, economically sound source of technical proteins, for use in industrial formulations, we might be able to achieve the same or better performance by a synthetic surfactant, or a blend of surfactants, at a lower concentration. This would mean a greener approach, comprising the application of renewable, biobased, less-toxic, more environmentally friendly ingredients. Such applications include environmental cleaning and remediation of accidental petroleum oil spills, industrial cleaning, agriculture, and other areas.

We were initially driven to this subject by multiple laboratory and field test observations that explicitly displayed an enhancement in the efficiency of a broad range of surfactants, including anionic, cationic, amphoteric, non-ionic, and theirblends, in the presence of low molecular weight proteins. These proteins were released to the fermentation broth by baker's yeast, in response to a sub-lethal heat shock. Cleaning and washing of solid surfaces contaminated by petroleum oil products, fat

*Corresponding author: Michael Goldfeld, Advanced BioCatalytics Corporation Irvine, California, USA, E-mail: mgoldfeld@abiocat.com

Received February 18, 2015; Accepted March 19, 2015; Published March 26 2015

Citation: Goldfeld M, Malec A, Podella C, Rulison C (2015) Proteins as Surfactant Enhancers for Environmental and Industrial Applications. J Pet Environ Biotechnol 6: 211. doi:10.4172/2157-7463.1000211

Copyright: @ 2015 Goldfeld M, et al. This is an open-access article distributed under the terms of the Creative Commons Attribution License, which permits unrestricted use, distribution, and reproduction in any medium, provided the original author and source are credited. 
and oil contaminants on high-temperature food processing equipment, wetting of, and spreading over hydrophobic surfaces, improvements in soil wetting in agriculture, better wetting, spreading and uptake of pesticides and micronutrients in foliar applications, improved cleaning, sanitizing and moisturizing in skin care, and modified effects of surfactants on biological membranes with implications to wastewater treatment - all these and a few other industrial implications have been identified and aggressively pursued. The IP for these applications is protected by a set of patents granted and pending [6-15]. Several articles have been previously published on these applications [16-18] and reported to professional meetings [19-21].

In this paper we present an account of the data generated with a more specific goal to clarify the effect of proteins (predominantly - small proteins) on the surfactant behavior using standard surface science techniques, such as measurements of the surface tension (ST), interfacial tension (IFT) in an oil/water system, and contact angles. The emphasis here is on the comparison of our technical, yeastderived protein adjuvant, to some well characterized small proteins, whose interactions with surfactants, such as sodium lauryl sulfate, were previously studied, and certain models of protein-surfactant interactions extensively discussed in the literature, as, for instance, in [22-26].

\section{Materials and Methods}

The following synthetic surfactants were explored in this study:

- $\quad$ Sodium lauryl ether sulfonate (SLES) 2 mol ethoxylated,

$\mathrm{n}-\left(\mathrm{CH}_{2}\right)_{10} \mathrm{CH}_{2}\left(\mathrm{OCH}_{2} \mathrm{CH}_{2}\right)_{2} \mathrm{OSO}_{3} \mathrm{Na}$, CAS \# 68585-34-2, as provided by Stepan Co., either in the form of STEOL ${ }^{\circledR}$ CS-230 (ca. 30\% active) or CS-270 (ca. $70 \%$ active);

- Sodium linear alkyl (predominantly dodecyl) benzene sulfonate (LAS), C12H25-C6H4-SO3Na, CAS \# 68081-81-2, as Stepan's BIO-SOFT ${ }^{\circledR}$ D-40 (35\% active);

- Non-ionic surfactant linear (C9-11) alcohol 6-ethoxylate (EO), n- $\mathrm{C}_{10} \mathrm{H}_{21} \mathrm{O}\left(\mathrm{CH}_{2} \mathrm{CH}_{20}\right) 6 \mathrm{H}$, CAS \# 68439-46-3, as Stepan's BIOSOFT N91-6 (100\% active);

- $\quad$ ALFOTERRA $^{\circledR}$ 145-4S (Sasol) branched C14-15 alkyl 4-propoxy sodium sulfonate, CAS \# 958238-82-9, ca. 90\% active;

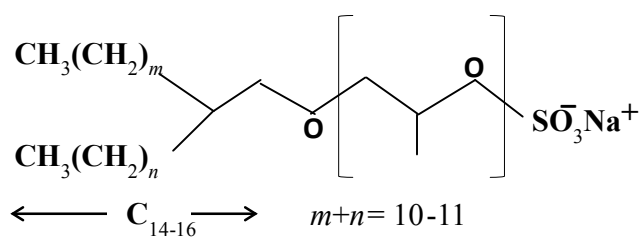

- AMMONYX $^{\circledR}$ LO, Stepan's amphoteric surfactant of the N-oxide type,

$$
\mathrm{CH}_{3}\left(\mathrm{CH}_{2}\right) 11-\mathrm{N}^{+}\left(\mathrm{CH}_{3}\right)_{2}-\mathrm{O} \text {; }
$$

- Stepan's TOXIMUL ${ }^{\circledR}$ TA-15, ethoxylated tallow amine, POE-15, CAS \# 61791-26-2<smiles>[2H]N(C)CCO[Hg]C</smiles>

Small proteins used here as adjuvants were human lysozyme (mol. mass $14.3 \mathrm{kDa}$ ) and $\beta$-lactoglobulin (mol. mass $18.4 \mathrm{kDa}$ ), both as lyophilized powders from Sigma-Aldrich.
Aqueous solutions of yeast protein extract were prepared from heat-shocked S. cerevisiae cultures as previously described [17] and applied either as is ("clear ferment", CF, ca. $3 \mathrm{mg} / \mathrm{mL}$ protein), or after concentrating about 5 times using membrane filtration (concentrated clear ferment, CCF).

Lipase from Candida rugosa was from Fisher Scientific. Activity of lipase enzyme was measured against peacock oil as a segregated substrate in the form of a droplet sitting at the tip of a capillary, and substrate digestion was monitored in the same setting which was applied in pendant drop tests.

The surface tension (ST) of aqueous solutions containing either surfactants, or their blends with protein, as well as interfacial tension (IFT) between those solutions and canola, or peacock oil, were determined by the pendant drop method, and contact angles at wetting/ spreading of solutions on the solid surface were all studied using Krüss tensiometers with a modified Krüss Drop Shape Analysis System DSA 10 that includes a digital camera to monitor droplet volume and shape, and use those for calculations of contact angles, ST and IFT (Figure 1). Each point in IFT and ST isotherms was recorded in duplicate. The difference was well within the dimension of the dots in the graphs, therefore no error bars are shown in the figures.

\section{Results and Discussion}

We focused our studies on rather low concentrations of both proteins and surfactants, typical of most industrial and environmental cleaning uses. The surfactants were below and slightly higher than the critical micelle concentration of the respective surfactant when taken alone, in the absence of protein. The most appropriate single quantifiable criterion for surfactant efficiency is the IFT value it provides. In this study, the IFT was measured in the water/canola oil two-phase system as a popular model for the assessment of surfactancy in the detergent industry. Essentially, all the results reported in this article may be schematically presented as a downward shift in the CMC of a surfactant when an appropriate amount of small proteins were added to the surfactant solution.

In Figure 2, this shift is illustrated for sodium lauryl ether sulfate (SLES) in the form of STEOL ${ }^{\circledR}$ CS-230 surfactant. Here one isotherm (green graph) is the IFT of the SLES solution, determined by the pendant drop method, as a function of surfactant concentration, at
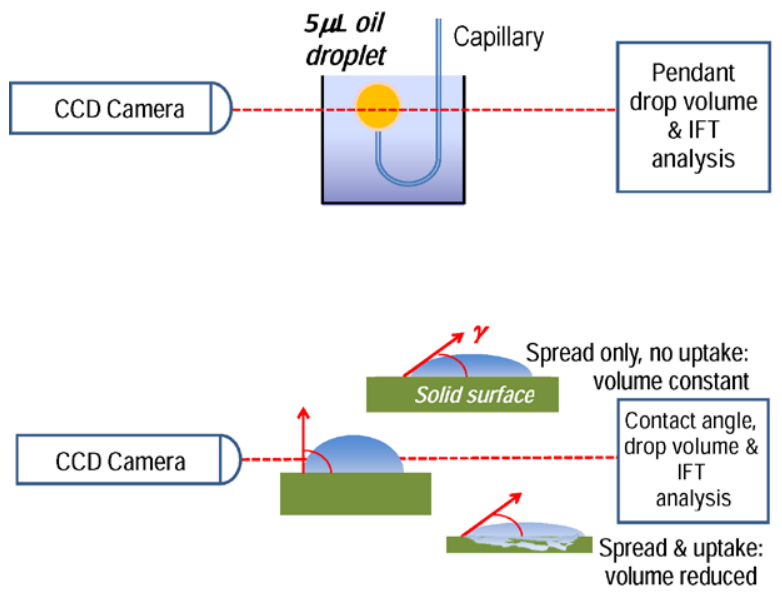

Figure 1: Surface methods schematics: pendant drop and contact angle measurements. 


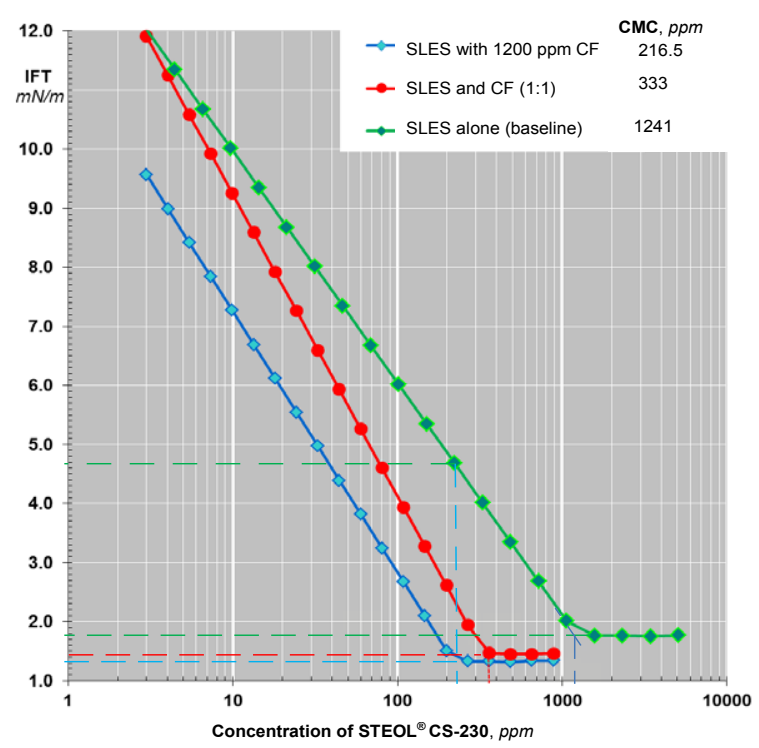

Figure 2: IFT isotherms $\left(22^{\circ} \mathrm{C}\right)$ of canola oil vs. aqueous SLES solution (STEOL ${ }^{\circledR}$ CS-230). Downward shift of SLES CMC in the presence of CF yeast exo-protein in both versions of the test: with (1:1) mixture of surfactant with the yeast extract CF protein synergist (red graph), and in the system with a permanent protein synergist content of $1200 \mathrm{ppmCF}$ along the entire isotherm (blue graph).

$22^{\circ} \mathrm{C}$, in the absence of any added proteins (base line). The red graph was obtained from mixtures (1:1 by weight) of the solutions of SLES with CF yeast protein. Finally, the blue graph is for the system in which the same concentration of CF protein was maintained (1,200 ppm), while the concentration of surfactant was steadily increased up to the CMC and slightly above.

The CMC value of $1,240.5 \mathrm{ppm}$ was found for the surfactant per se, while in the presence of protein, CMC shifted towards lower concentrations of surfactant: to $333 \mathrm{ppm}$ in (1:1) mixtures, and to 216.5 ppm with a higher constant background concentration of protein at $1,200 \mathrm{ppm}$. Minimal IFT values also tend to decrease in the presence of protein. However, it is not the minimal IFT value that is essential, but rather that this minimal IFT can be obtained at a substantially lower concentration of the surfactant. The minimal IFT $=1.75 \mathrm{mN} / \mathrm{m}$ without the protein synergist is achieved at $1,240.5 \mathrm{ppm}$ surfactant, while for the (1:1) protein synergist even somewhat lower IFT $=1.42 \mathrm{mN} / \mathrm{m}$ was obtained at a surfactant concentration of $333 \mathrm{ppm}$, and a close value of $1.3 \mathrm{mN} / \mathrm{m}$ found with $1,200 \mathrm{ppm}$ CF. In other words, we may apply about $83 \%$ less surfactant to reach the same, or somewhat stronger level of surfactancy, with the protein synergist, as compared to the surfactant taken alone. Assuming the cost of CF is similar to the costs of the surfactants, that means over $60 \%$ net cost reduction.

Yeast extract is not a purified protein, but contains other ingredients commonly found in the yeast fermentation broth. It was essential to provide some evidence that the synergistic enhancement of surfactancy is due to proteins, i.e. macromolecular component of the extract. For this purpose the CF solution was concentrated using membrane filtration, and this way the content of non-filtering material was increased approximately 5.12 times. This liquid, concentrated clear ferment (CCF), was then diluted 5 times with DI water and used in two parallel tests with the same surfactant, STEOL ${ }^{\circledR} \mathrm{CS}-270$, alone, and with $\mathrm{CF}$ at 1,200 ppm, or CCF at $233 \mathrm{ppm}$. Figure 3 shows, again, a downward shift in SLES CMC in the presence of the protein synergist. If the protein species is responsible for the shift, both the isotherms are expected to coincide, since CCF stock solution is essentially five time concentrated CF, this is exactly what was observed.

In Figures 4-6, similar data are presented for three other common surfactants, two of them being anionic sulfonates, and one - a nonionic alcohol ethoxylate. Results for the anionics were similar to those for SLES: for both, a profound downward shift in CMC and

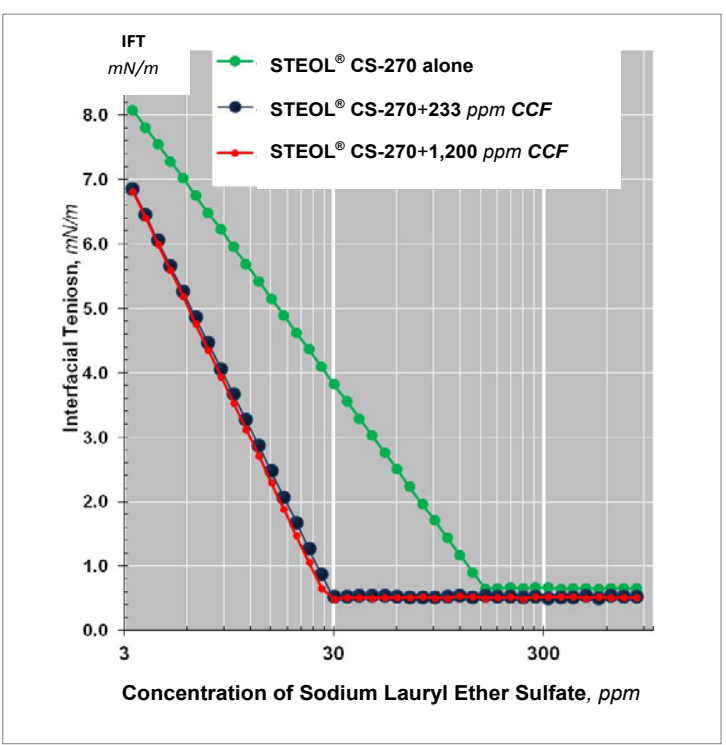

Figure 3: IFT isotherms in canola oil/aqueous solution of STEOL ${ }^{\circledR}$ CS-270 surfactant Downward shift of SLES CMC in the presence of permanent concentration of CF yeast exo-protein 1,200 ppm) is observed. After CF was ca. five times concentrated using membrane filtration, this solution of concentrated protein synergist, CCF, was added to surfactant in the amount of $233 \mathrm{ppm}$. Isotherms with CF and CCF at these settings practically coincided, as expected.

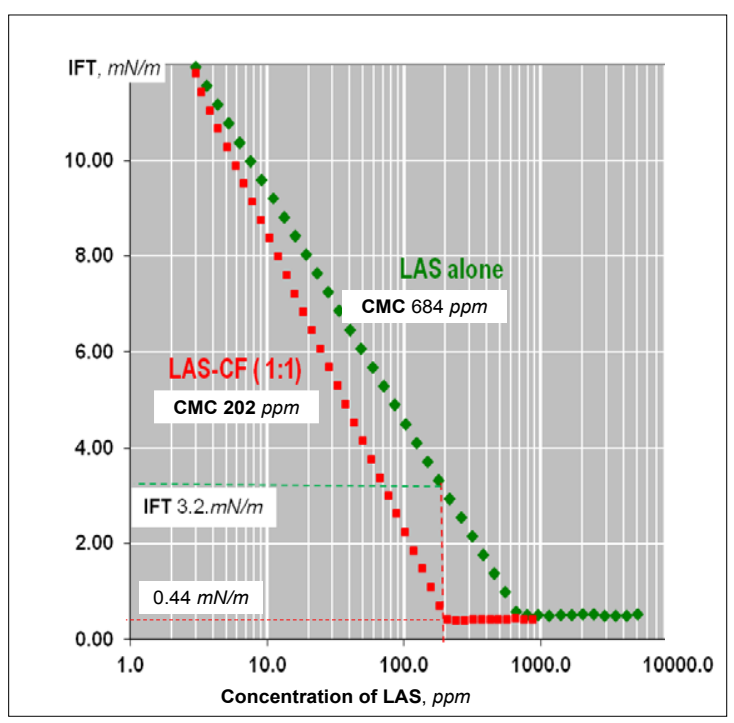

Figure 4: IFT isotherms in canola oil/aqueous solution of LAS surfactant. Downward shift of CMC in the presence of CF yeast exo-protein. 


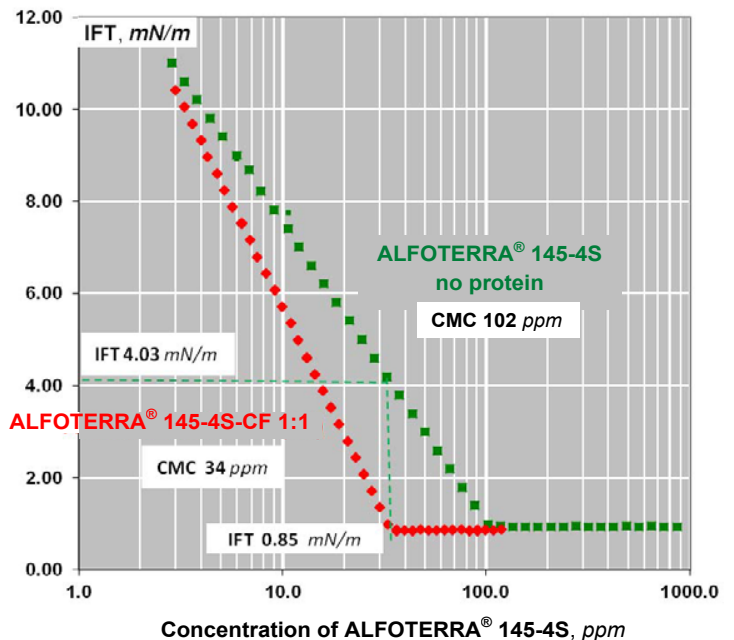

Figure 5: IFT isotherms in canola oil/aqueous solution of ALFOTERRA ${ }^{\circledR}$ $145-4 \mathrm{~S}$ surfactant. Downward shift of CMC in the presence of CF yeast exoprotein.

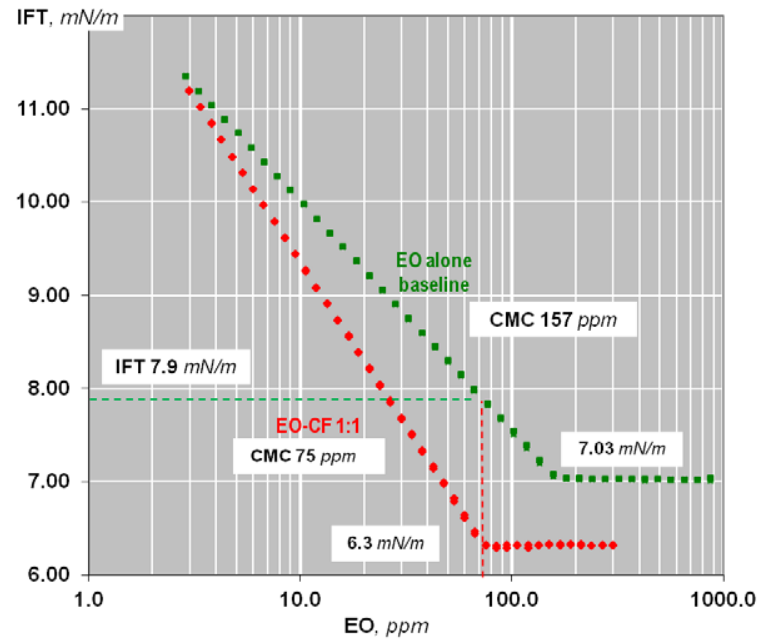

Figure 6: IFT isotherms in canola oil/aqueous solution of non-ionic alcohol ethoxylate BIO-SOFT ${ }^{\circledR}$ N-91.6 surfactant. Downward shift of CMC in the presence of CF yeast exo-protein and reduction of minimal achieved IFT.

slight further reduction of the minimal achieved IFT in the presence of CF protein were observed. For the non-ionic alcohol ethoxylate $\left(\mathrm{BIO}-\mathrm{SOFT}^{\circledR} \mathrm{N} 91.6\right)$ the picture is qualitatively the same (Figure 6). However, the protein-induced changes develop on a rather weak background reduction in IFT, characteristic for non-ionics when taken alone, rather than as a co-surfactant to an anionic main surfactant: CMC shifted from 157 to $75 \mathrm{ppm}$, while IFT was reduced from about $12 \mathrm{mN} / \mathrm{m}$ (no surfactant) down to $7.03 \mathrm{mN} / \mathrm{m}$ with surfactant alone, and to $6.3 \mathrm{mN} / \mathrm{m}$ in the presence of the protein synergist.

Data on CMC shifts induced by the yeast CF exo-protein are further summarized in the Figure 7 diagram, where the lower CMC achieved for a (1:1) mix of a surfactant and protein synergist is taken as $100 \%$ for each surfactant (red columns), while green columns show CMC observed with the same surfactant taken alone. For anionics, the reduction of CMC was observed in the range of 67 to $73 \%$. Less pronounced CMC shift for non-ionic surfactant, $52 \%$ for the alcohol ethoxylate, is in line with the commonly accepted notion in the literature that proteins bind a lesser number of non-ionic surfactant molecules and this binding is also weaker. Figure 8 summarizes shifts in IFT values for the same four surfactants, measured at the surfactant concentration equal to its CMC in the presence of the protein synergist. Minimal IFT in the (1:1) surfactant-protein mix is again taken as $100 \%$ for each surfactant (red columns). The most dramatic drop in IFT was observed for linear alkylbenzene sulfonate (over 7 times). Substantial IFT reduction occurred also with branched alkyl propoxylated sulfonate (4 times) and lauryl ether sulfate ( 2.5 times). A much less pronounced effect could be seen for the nonionic alcohol ethoxylate, as expected.

In Figure 9, the IFT for a proprietary blend of surfactants in

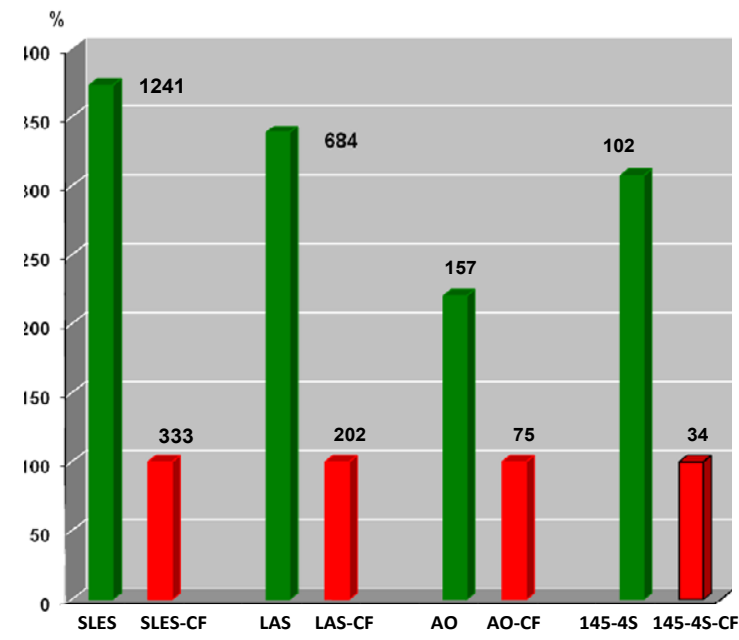

Figure 7: Summary of the yeastCF exo-protein on CMC of synthetic surfactants. In all cases, (1:1) mix of surfactant with CF is taken as $100 \%$ (red columns). CMC values (ppm surfactant) are indicated for each surfactant and its mixture with protein.

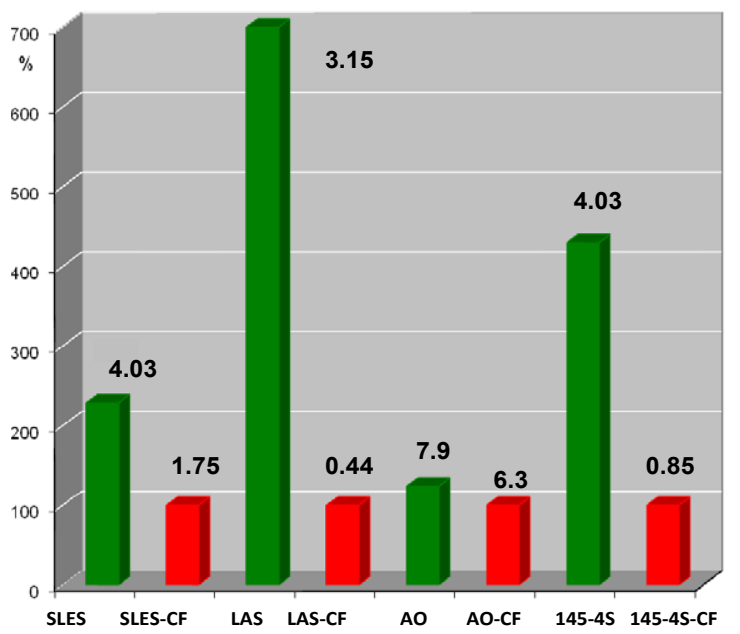

Figure 8: Yeast extract CF exo-protein effect on IFT at a surfactant concentration equal to its CMC with protein synergist. IFT in a (1:1) mix of surfactant and CF is taken as $100 \%$ (RED columns). Numbers IFT values for each system in $\mathrm{mN} / \mathrm{m}$. 
Citation: Goldfeld M, Malec A, Podella C, Rulison C (2015) Proteins as Surfactant Enhancers for Environmental and Industrial Applications. J Pet Environ Biotechnol 6: 211. doi:10.4172/2157-7463.1000211

Page 5 of 8

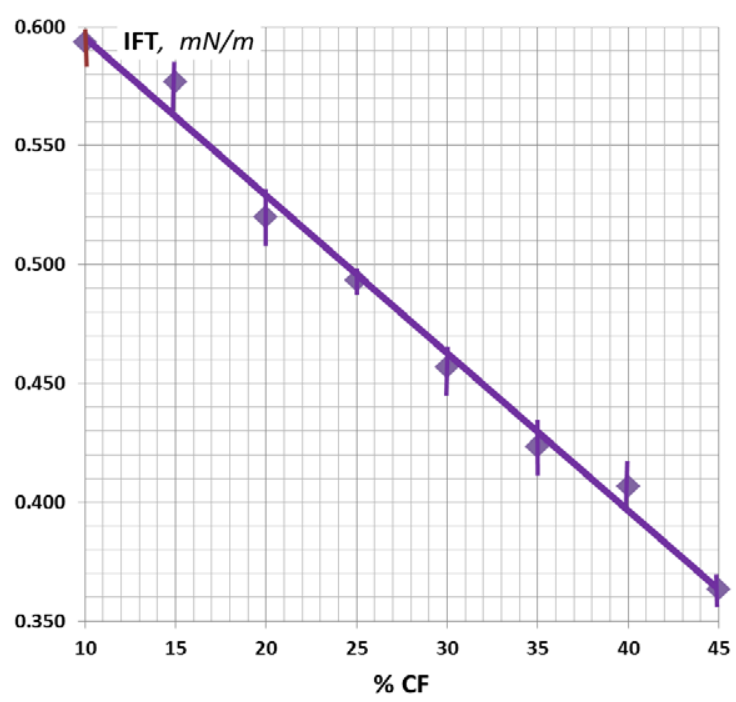

Figure 9: Tuning the performance of a proprietary blend of surfactants by yeast CF exo-protein synergist. IFT in canola oil/water system as function of CF protein percent. Concentration of surfactants is the same all over the graph.

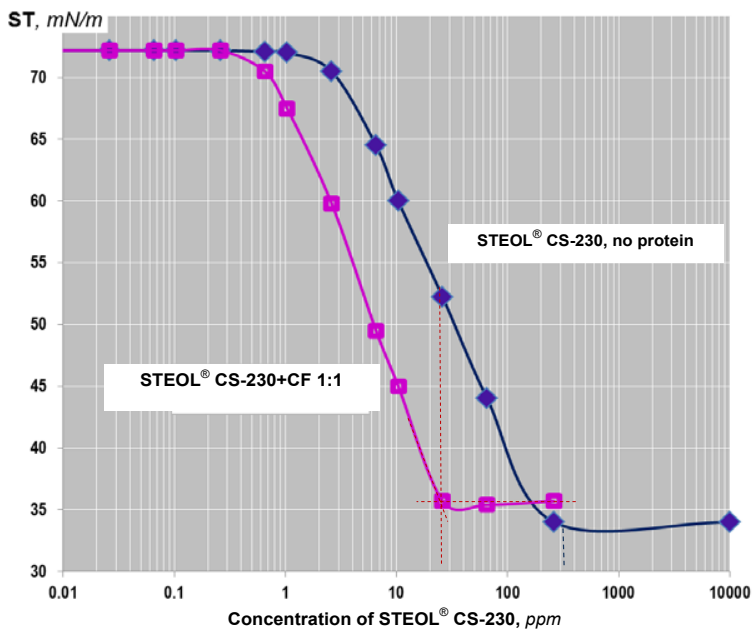

Figure 10: ST isotherms of aqueous solution of STEOL ${ }^{\circledR} \mathrm{CS}-230$ surfactant. Downward shift of SLES CMC in the presence of CF yeast exo-protein. At each point, surfactant and protein solutions were mixed (1:1).

the same canola oil/water system, is presented as a function of the yeast $\mathrm{CF}$ protein synergist percent. Within a broad range of protein concentrations, a nearly linear dose response has been observed.

Corroborating data on protein-induced enhancement of surfactancy, as seen by the downward CMC shift, were further obtained, for the same and a few other surfactants, by measuring surface tension (ST rather than IFT) of aqueous solutions of surfactants and their blends with protein synergist. Figures 10-12 reflect these data. It is clear that the turning points of the graphs shift to considerably lower concentrations of surfactants, from where they were for pure surfactants, to their (1:1) mixtures with yeast extract CF protein. With the amphoteric surfactant, AMMONYX ${ }^{\circledR} \mathrm{LO}$, a considerable downward shift in CMC was achieved in the presence of the CF protein synergist, from ca. $200 \mathrm{ppm}$ down to $15 \mathrm{ppm}$. The minimal attainable ST value was also slightly lower for the protein - AMMONYX ${ }^{\circledR}$ blend, than for surfactant alone. With lauryl ether sulfate, the CMC decrease was about an order of magnitude, similar to the shift in IFT isotherm. However, no decrease in minimal attainable ST was found in this case with CF. So far, we only used yeast extract material as our protein synergist. It was important to see if the phenomenon of the surfactancy enhancement by small proteins may be of general nature, so we further used two well characterized individual proteins: lysozyme and $\beta$-lactoglobulin. Both are rather small proteins with their mol. masses in the 10 to $20 \mathrm{kDa}$ range. The SLES surfactant, used in these studies, STEOL ${ }^{\circledR}$ CS-270, was the same which was previously studied in certain detail with the yeast extract CF and CCF proteins. All these experiments were conducted with a constant background protein concentration along the entire IFT isotherm. The results are summarized in Figure 13. Increasing the

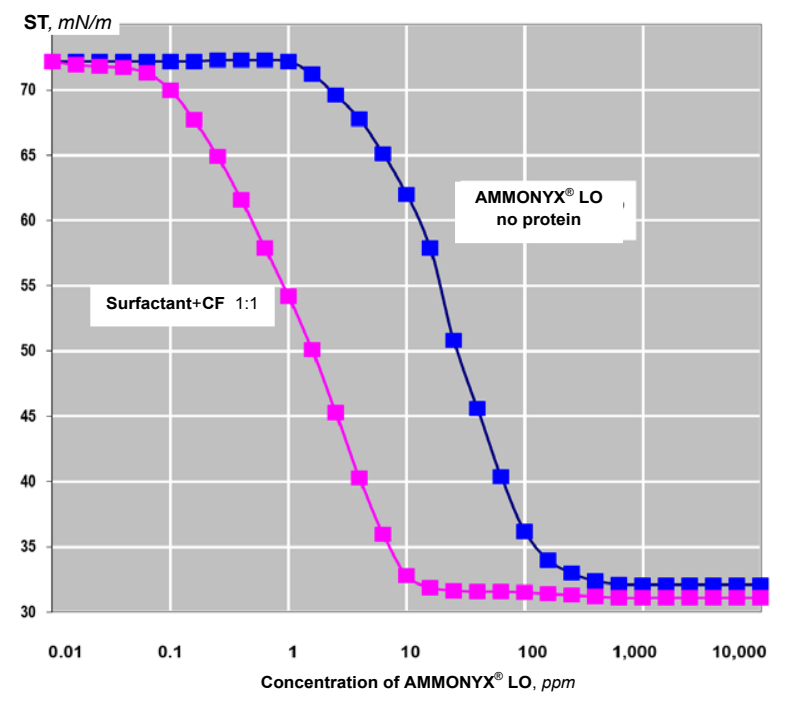

Figure 11: ST isotherms of aqueous solution of Stepan's AMMONYX ${ }^{\circledR}$ LO surfactant. Downward shift of CMC is observed in the presence of yeast CF exo-protein. At each point, surfactant and protein solutions were mixed (1:1).

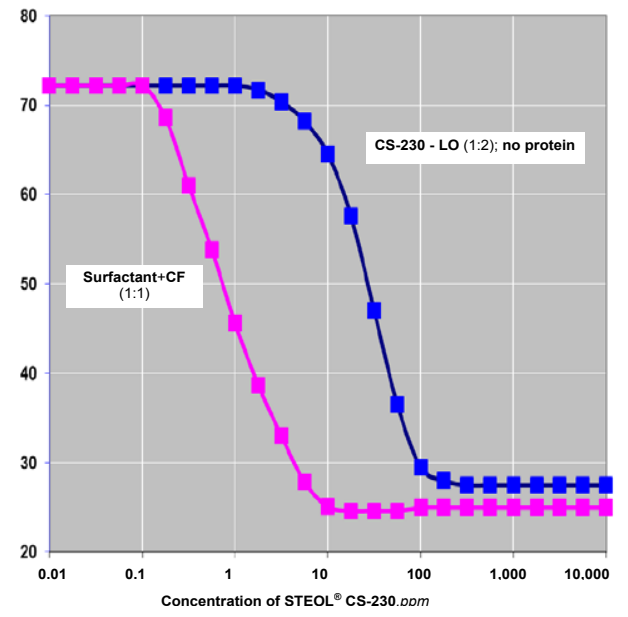

Figure 12: ST isotherms of aqueous solution of a mixture of anionic STEOL CS-230 (main surfactant) withamphoteric AMMONYX ${ }^{\otimes}$ LO co-surfactant (2:1). Downward shift of SLES CMC in presence of yeast CF exo-protein. At each point, surfactant and protein solutions were mixed (1:1). 


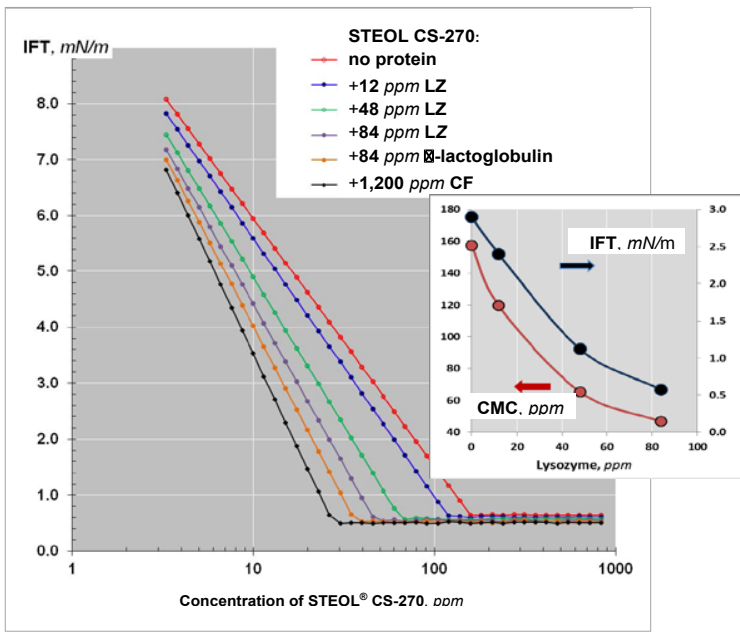

Figure 13: Effect of lysozyme (LZ) and $\beta$-globulin. IFT isotherms of canola oil/aqueous solution of STEOL ${ }^{\circledR} \mathrm{CS}-270$ surfactant. Downward shift of CMC in the presence of increasing concentrations of lysozyme. Effect of $\beta$-globulin is slightly stronger than that of lysozyme at the same concentration (84 ppm). For comparison, the IFT isotherm in the presence of $1,200 \mathrm{ppm}$ CF yeast protein presented at the same figure, displaying the lowest CMC recorded. Insert: CMC as function of lysozyme concentration, and IFT at SLES concentration equal to the lowest achieved $\mathrm{CMC}$ with lysozyme.

concentration of lysozyme in the range of zero to $84 \mathrm{ppm}$ resulted in a reduction of CMC. The CMC shift dose-response is shown in the insert graph of Figure 13. $\beta$-Lactoglobulin, added at the same concentration as lysozyme (84 ppm) provided a slightly stronger downward shift in CMC. For comparison, similar data are shown at the same graph for yeast CF protein. The latter was added at 1,200 ppm. However, taking into account that the extract contains about $3 \mathrm{mg} / \mathrm{mL}$ protein, that provides a comparable net amount of protein at ca. $40 \mathrm{ppm}$. In these tests, CF provided a somewhat stronger, but comparable downward shift in CMC, as lysozyme and $\beta$-lactoglobulin. Although the minimal attained IFT tends to lower values when proteins were added, this trend is weakly pronounced and does not appear to provide substantial additional benefits.

These results clearly indicate that small proteins indeed enhance the activity of synthetic surfactants in the manner similar to the yeast extract protein, so that the phenomenon of synergistic enhancement of surfactancy by small proteins is of a rather general nature, not limited to the specific properties of yeast protein extract.

Altogether, the data provide a strong indication that small proteins at low concentrations, comparable to those of the surfactant itself, act as synergists of surfactancy, reducing CMC, ST, and IFT of the surfactants to levels that cannot be achieved with the same surfactants in the absence of proteins. That may be not true for bigger proteins, and at higher protein concentrations. For instance, Nishikido et al. [27] reported that bovine serum albumin (BSA, mol. mass $66.5 \mathrm{kDa}$ ) present in the amount of 70 to $1000 \mathrm{ppm}$ increased (rather than decreased) ST and shifted the CMC of non-ionic hexa-ethoxylated lauryl alcohol to higher values. Small upward shifts in ST and CMC for the same surfactant were observed in the presence of lysozyme when its concentration varied in the range of 15,000 to $150,000 \mathrm{ppm}$. Aggregation and conformational transitions of both lysozyme and $\beta$-lactoglobulin were considered as factors affecting the binding of non- ionic and anionic surfactant to proteins, among other effects $[27,28]$.

Although measurements of IFT and ST in protein-surfactant solution blends may look, at a first glance, as a merely an academic exercise, the following few examples will serve as demonstration of the significance of this approach as a rationale and a predictive tool for major industrial implications.

\section{Foliar uptake enhancement}

Improving spreading, wetting and uptake by leaves of green plants by protein synergists in foliar application of bio-actives (such as micronutrients, pesticides, etc.) is an important part of agricultural applications of surfactants. Often, only a tiny fraction (under $1 \%$ by some estimations) of pesticides applied as a foliar spray reaches the target site in plants - most of the material is lost due to the fact that waterborne solutions do not easily wet and penetrate the surface of leaves coated with a hydrophobic waxy cuticle $[29,30]$. Liquid droplets slide from the surface of leaf to the soil thus the pesticide is lost for its intended purpose and the instead contributes to the environmental pollution. Therefore, surfactants serve as common adjuvants in pesticides and some foliar micronutrient formulations. The protein synergist proved to improve the efficiency of such adjuvants. Figure 14 shows typical results for the uptake of aqueous solutions of four surfactants belonging to different classes, taken alone and in combination with the yeast extract $\mathrm{CF}$ protein synergist. The experimental setting was as shown in Figure 1 for the contact angle measurements, where the "solid surface" is that of a green leaf of cabbage. The latter is known to have its leaves coated with a tough waxy cuticle, resisting spreading, wetting and uptake. For each of the surfactants, the efficiency of wetting as assessed by the rate of spreading and uptake of the solution by the green leaf dramatically improved in the presence of the protein synergist. Some details of these tests were also described in [9].

Table 1 summarizes kinetic parameters of droplet evolution for different surfactants and their blends with the protein synergist. Neither one of the four surfactants without protein support provided complete uptake of the solution within a reasonable time. However,

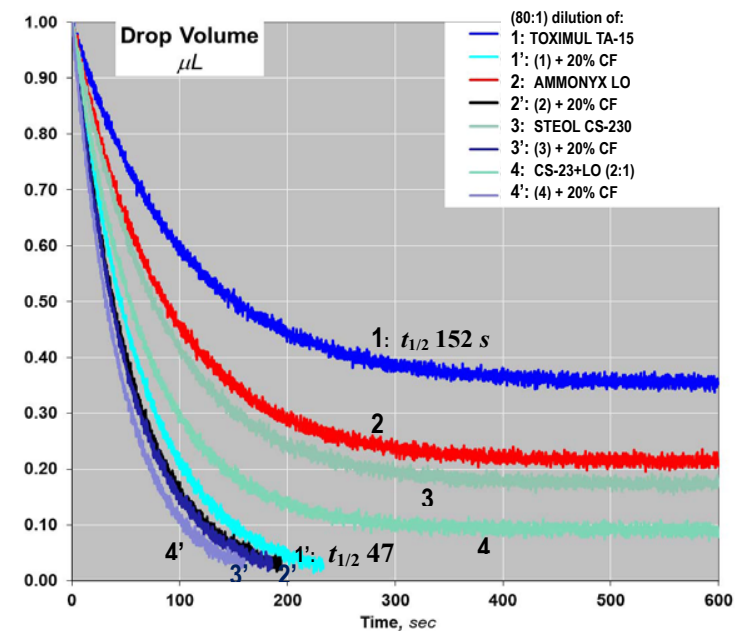

Figure 14: Kinetics of drop volume reduction due to uptake of the solution by a cabbage leaf surface. Four surfactants used each at a concentration slightly exceeding their respective CMC. Primed numbers indicate the same surfactant with addition of $20 \%$ of a yeast CF protein synergist. In all cases, considerable acceleration of spreading, wetting and uptake of the solution by the leave have been observed. 


\begin{tabular}{|c|c|c|c|c|}
\hline & $\begin{array}{c}\begin{array}{c}\text { Average } \\
\text { half-life }\end{array} \\
\text { of Droplet uptake, sec }\end{array}$ & $\begin{array}{l}\text { Average Time to } \\
\text { Complete Droplet } \\
\text { uptake, sec }\end{array}$ & $\begin{array}{l}\text { Equilibrium Non- } \\
\text { Penetrated Drop } \\
\text { Volume, } \mu \mathrm{L}\end{array}$ & $\begin{array}{c}\text { Equilibrium } \\
\text { Contact Angle, degree }\end{array}$ \\
\hline TOXIMUL ${ }^{\circledR}$ TA-15 & 152 & $600+$ & 0.35 & 28.6 \\
\hline TOXIMUL ${ }^{\circledR}$ TA-15+ Protein & 47 & 233 & 0 & 0 \\
\hline AMMONYX ${ }^{\circledR}$ LO & 123 & $600+$ & 0.21 & 18.8 \\
\hline AMMONYX ${ }^{\circledR}$ LO+ Protein & 42 & 194 & 0 & 0 \\
\hline STEOL ${ }^{\circledR}$ CS-230 & 71 & $600+$ & 0.18 & 18.1 \\
\hline STEOL ${ }^{\circledR}$ CS-230+Protein & 28 & 185 & 0 & 0 \\
\hline STEOL ${ }^{\circledR}$ CS-230+ AMMONYX ${ }^{\circledR}$ LO (2:1) & 51 & $600+$ & 0.09 & 12.5 \\
\hline STEOL CS-230+ AMMONYX ${ }^{\circledR}$ LO (2:1) + Protein & 24 & 159 & 0 & 0 \\
\hline
\end{tabular}

Table 1: Yeast extract CF protein synergist (20\%) enhances and accelerates the wetting, spreading, and uptake of each of the four surfactant solutions applied to the cabbage leaf surface as a $1 \mu \mathrm{L}$ droplet.

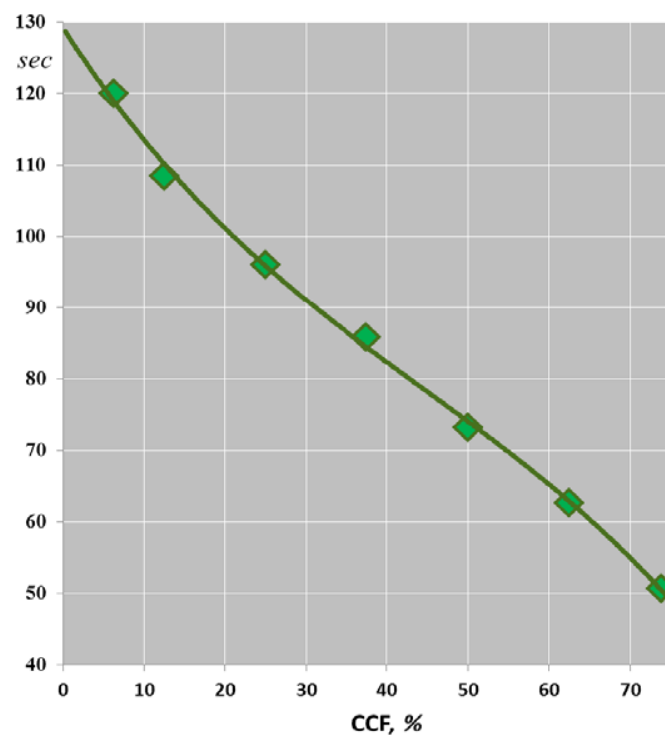

Figure 15: Tuning the uptake rate of a surfactant solution by cabbage leaf. Time of complete (95\%) droplet uptake as function of the yeast protein synergist CCF concentration.

the same surfactants blended with the protein ensured full uptake within 4 minutes or less. Without the protein synergist, 10 to $40 \%$ of the solution remained on the leaf surface 10 minutes after application, while with protein no solution remained on the surface of the leaf within 4 minutes.

Figure 15 shows that the efficiency of the wetting, spreading and uptake of the surfactant solution by the green leaf increases with addition of the protein synergist in a dose-dependent manner: the half-life of solution uptake dropped from 120 down to $50 \mathrm{sec}$ when the percent of CCF in the formulation increased from 5 to $75 \%$.

\section{Activation of industrial enzymes}

Figure 16 illustrates the application of surfactants, when they are used in conjunction with certain enzymes that process water-insoluble substrates. Here, bacterial lipase was applied to digest peacock oil in the pendant drop setting. Pendant droplet volume and shape was recorded and analyzed as outlined in Figure 1, and the droplet volume decrease was used as a measure of substrate consumption. Some details of these tests can be found in [13]. Lipase is known to be activated by certain surfactants $[31,32]$. The enzyme was applied either alone, or in combination with a blend containing surfactants and a protein synergist, or with the same blend of surfactants without the

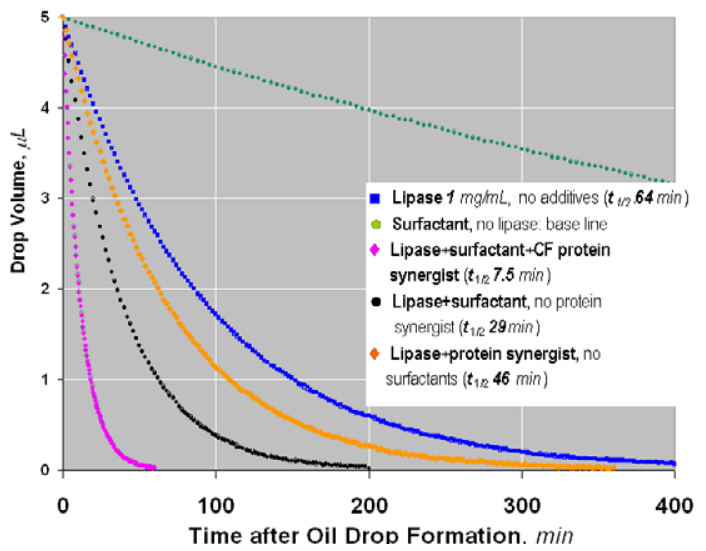

Figure 16: Kinetics of drop volume reduction due to digestion of peacock oil droplet (initial volume $5 \mu \mathrm{L}$ ) by lipase. Lipase is activated by surfactants. Comparison of a proprietary surfactant blend with and without protein synergist. Protein accelerated oil consumption ca. four times.

protein. Surfactants per se (without the enzyme) provided slow, steady solubilization of the oil droplet (green baseline in Figure 16). In the presence of lipase (no surfactants) the half-life of the droplet was 64 min. Lipase in the presence of surfactant (no protein) processed the droplet with a half-life of $29 \mathrm{~min}$, while lipase activated by the full blend of surfactants and protein, processed the substrate with a half-life of $7.5 \mathrm{~min}$. Thus, the protein synergist accelerated the performance of the enzyme about four times as compared to the same surfactant without the protein.

\section{Conclusions}

Experimental data presented in this article indicate that small proteins may significantly improve the performance of certain surfactants in industrial, agricultural, and environmental certain surfactants applications.

Synergistic enhancement of the efficiency of surfactants by small proteins appears to be a general phenomenon, with surfactants of various classes - anionic, cationic, non-ionic and amphoteric. Such an enhancement is reflected and may be predicted using small-scale bench studies by standard surface science methods, as reduction in surface and interfacial tension, downward shifts in critical micelle concentration, and improved wetting and spreading over solid surfaces. The protein synergist may be an individual small protein, such as lysozyme, or $\beta$-lactoglobulin, or a protein in an industrial liquor, such as stress exoprotein released to the fermentation broth by baker's yeast in response to a mild, non-lethal heat shock. 
Citation: Goldfeld M, Malec A, Podella C, Rulison C (2015) Proteins as Surfactant Enhancers for Environmental and Industrial Applications. J Pet Environ Biotechnol 6: 211. doi:10.4172/2157-7463.1000211

By using a protein synergist, the same surfactancy may be provided at a lower level of synthetic surfactant, while part of the surfactant is replaced by a protein synergist. Otherwise, a superior performance can be achieved by using a blend of a surfactant with a protein. In both cases, replacing part of surfactant with a protein synergist improves the green profile of the formulation and reduces its environmental impact. Although individual proteins are generally more expensive than synthetic surfactants, the yeast stress protein production could present a process that provides the protein synergist at a competitive cost making this material a potentially economically viable ingredient for industrial cleaner formulations and in other large-scale areas of surfactant applications.

\section{Acknowledgment}

Continuous support and inspiration from John W. Baldridge, founder and CEO of the Advanced BioCatalytics Corp. is greatly appreciated.

\section{References}

1. Otzen D (2011) Protein-surfactant interactions, a tale of many states. Biochim Biophys Acta 1814: 562-591.

2. Randolph TW, Jones LS (2002) Surfactant-Protein Interactions. Pharm Biotechnol 13: 159-175

3. Jones MN (1996) Protein-surfactant interactions. In: Surface activity of proteins Magdassi S, ed. Marcel Dekker, New York, USA: 237-284.

4. Bhuyan AK (2009) On the mechanism of SDS-induced protein denaturation. Biopolymers 93: 186-199.

5. Holmberg K, Jönsson B, Kronberg B, Lindman B (2002) Surfactants and polymers in aqueous solutions. Ch.14: Surfactant-protein mixtures. John Wiley and Sons: $305-315$.

6. Surfactant composition with a reduction of surface tension, interfacial tension, and critical micelle concentration using a protein-based surfactant synergist.

7. Septic system cleaning

8. Septic system cleaning compositions

9. US Patent $8,871,682$. Protein compositions for plant treatment.

10. US Patent $8,871,698$. Cleaning compositions and methods for reducing burnton food and oil residues.

11. US Patent $8,894,861$. Method of herding and collection of oil spilled at the aquatic surface.

12. US Patent Application 20130251660. Skin wetting compositions and methods.

13. US Patent Application 20130252287. Protein-enhanced surfactants for enzyme activation.

14. US Patent Application 20130313465. Firefighting and fire retardant compositions.

15. US Patent Application 20140248373. Enhanced performance hydrogen peroxide formulations for comprising proteins and surfactants.

16. Baldridge JW, Podella CW (2005) Changing the nature of surfactants. Industria Biotechnology 1: 288-291.

17. Podella CW, Hooshnam N, Krassner SM, Goldfeld MG (2009) Yeast proteinsurfactant complexes uncouple microbial electron transfer and increase transmembrane leak of protons. J Applied Microbiol 106: 140-148.
18. Goldfeld MG, Podella CW (2012) Out of Sight, but Still a Blight? Petroleum Oil Dispersants: Addressing the Environmental Impact. J Pet Environ Biotechnol Vol 3: 6-e114.

19. Goldfeld MG, Podella CW, Baldridge JW, Rulison C (2014) Environmentally Relevant Technology Based on Protein-Enhanced Surfactants, 11th Annual BIO World Congress on Industrial Biotechnology, 2014, Philadelphia, PA.

20. Goldfeld MG, Podella CW, Rulison C (2012) Protein-enhanced surfactants for cleaning, water treatment and bioremediation. 243 $3^{\text {rd }}$ ACS National Meeting, San Diego, California, USA: 25-29.

21. Podella CW, Baldridge JW, Krassner S, Sasaki S, Goldfeld MG (2008) Changing the nature of surfactants: a new paradigm for water processing. Water Unites International. Conference, Irvine, California 1-5.

22. Valstar A, Brown W, Almgren M (1999) The Lysozyme-Sodium Dodecyl Sulfate System Studied by Dynamic and Static Light Scattering. Langmuir 15: 23662374.

23. Valstar A (2000) Protein-Surfactant Interactions, PhD Thesis, Acta Universitatis Upsalinensis. Uppsala: 7-50.

24. Fukushima K, Murata Y, Sugihara G, Tanaka M (1981) The Binding of Sodium Dodecyl Sulfate to Lysozyme in Aqueous Solutions. Bull Chem Soc Japan 54 3122-3127.

25. Faustino CMC, Calado ART, Garcia-Rio L (2009 Gemini surfactant-protein interactions: effect of $\mathrm{pH}$, temperature, and surfactant stereochemistry. Biomacromolecules 10: 2508-2514.

26. Andersen KK (2009) Protein-surfactant interactions: the interplay between structure, stability and kinetics. PhD Thesis, Aalborg University Dept. of Life Sciences, Denmark.

27. Nishikito N, Takahara T, Kobayashi H, Tanaka M (1982) Interaction between hydrophilic proteins and non-ionic detergents by surface tension measurements. Bull Chem Soc Japan 55: 3085-3088.

28. Jones MN, Wilkinson A (1976) The interaction between Beta-lactoglobulin and sodium N-dodecyl sulphate. Biochem J 153: 713-718.

29. Kirkwood RC (1999) Recent developments in our understanding of the plant cuticle as a barrier to the foliar uptake of pesticides. Pesticide Science 55 69-77.

30. Fernandes V, Brown PH (2013) From plant surface to plant metabolism: the uncertain fate of foliar-applied nutrients. Front Plant Sci. 4: article 289.

31. Xia J, Chen X, Nnannal A (1996) Activity and stability of Penicillium cyclopium lipase in surfactant and detergent solution. J Am Oil Chem Soc 73: 115-120.

32. Reis PM, Raab TW, Chuat JY, Leser ME, Miller R, et al. (2008) Influence of Surfactants on Lipase Fat Digestion in a Model Gastro-intestinal System. Food Biophysics 3: 370-381. 